\title{
Nöroblastomlu Çocukların Klinik Özellikleri
}

\author{
The Clinical Characteristics of Children with Neuroblastoma
}

\begin{abstract}
Betül Sevinir, Metin Demirkaya, Salih Güler, Hanife Hekim*, Filiz Akaltun*

Uludağ Üniversitesi Tıp Fakültesi, Çocuk Sağlığı ve Hastalıkları Anabilim Dall, Çocuk Onkoloji Bilim Dall, Bursa, Türkiye

*Uludağ Üniversitesi Tıp Fakültesi Çocuk Sağı̆̆ı ve Hastalıkları Anabilim Dalı, Bursa, Türkiye
\end{abstract}

Yazışma Adresi/Address for Correspondence Dr. Betül Sevinir, Uludağ Üniversitesi Tip Fakültesi Çocuk Sağlı̆ı ve Hastallkları Anabilim Dall, Çocuk Onkoloji Bilim Dall, Bursa, Türkiye Tel.: +9022429504 43 E-posta: bsevinir@uludag.edu.tr

Geliş Tarihi/Received: 30.10.2012 Kabul Tarihi/Accepted: 25.01.2013

(c) Güncel Pediatri Dergisi, Galenos Yayınevi tarafindan basilmıştr.

(c) The Journal of Current Pediatrics, published by Galenos Publishing.

\section{ÖZET}

Giriş: Bu çalışmanın amacı nöroblastomlu (NBL) çocuklarda tanısal özelliklerin belirlenmesidir. Gereç ve Yöntem: Hastaların kayıtları retrospektif olarak değerlendirildi. Yaş, başvuru yakınmaları ve süreleri, tümör yerleşimi ve evre belirlendi. Hemogram, laktat dehidrogenaz (LDH) ve VMA sonuçları kaydedildi. Veriler istatistiksel olarak karşılaştıııldı.

Bulgular: NBL'lu 115 hastanın ortalama yaşı 2,57 $\pm 2,49$ yıl (sınırlar $0-12$ ) olup \%32'si bir yaşından, \%89'u ise beş yaşından küçüktü. Hastaların \%74,8'inde abdominal (\%66'sı adrenal, \%8,8'i adrenal dışı), \%12'sinde paraspinal, \%7'sinde mediastinal ve \%3,5'inde pelvik kitle saptandı. Olguların \%30,4'ünde evre 1 ve 2, \%13'ünde evre 3, \%46,1'inde evre 4 ve $\% 10,4$ 'ünde evre 4S hastalık belirlendi. Olguların \%11'i klinik özellikler, sitolojik bulgular ve VMA ölçümü ile tanı aldı. VMA yüksekliği \%83 oranında idi. Ortanca yakınma süresi 6,5 hafta olarak bulundu. En sık gözlenen yakınmalar solukluk, karın şişliği, karın ağrısı ve kemik ağrısı idi.

Sonuç: NBL küçük çocukların tümörüdür. Primer yerleşime ve yaygınlığa göre klinik bulgular değiş̧mektedir. Anemi, karın ağrısı ve kemik ağrıları uyarıcı bulgulardır. (Güncel Pediatri 2013; 11: 6-12)

Anahtar kelimeler: Nöroblastom, klinik özellikler, metastaz

\section{SUMMARY}

Introduction: The aim of this study was to evaluate the diagnostic characteristics of children with neuroblastoma (NBL).

Materials and Methods: Hospital records were reviewed retrospectively. Age, symptoms and their durations, tumor site, stage and results of complete blood count, LDH and VMA were recorded. Statistical comparisons and calculations were made.

Results: The mean age at diagnosis was $2.57 \pm 2.49 \mathrm{yrs}$ (ranges $0-12$ ). Of children, $89 \%$ were under 5 years and $32 \%$ were below 1 year. The most common tumor sites were abdomen [74.8\%; (adrenal 66\%), (non-adrenal 8.8\%)], paraspinal region (12\%), chest $(7 \%)$ and pelvis (3.5\%). Most of the tumors were in advanced stage (stage 1 and $2=30.4 \%$, stage 3 and $4=13 \%$ and $46,1 \%$ and stage $4 \mathrm{~S}=10.4 \%$ ). The diagnosis was made from bone marrow cytology and increased VMA in $11 \%$ of the cases. VMA level was high in $83 \%$ of the patients. Median duration of symptoms was 6.5 weeks. The most frequent complaints were pallor, abdominal mass, abdominal pain and bone pain.

Conclusions: NBL mainly involves young children. Clinical presentation varies with primary tumor site and dissemination. Anemia, abdominal and bone pain have diagnostic significance. (Journal of Current Pediatrics 2013; 11: 6-12)

Key words: Neuroblastoma, clinical presentation, metastasis

\section{Giriş}

Nöroblastom (NBL) çocuklarda en sık görülen ekstrakraniyal solid tümördür. Pediatrik tümörlerin \%710'unu oluşturur (1). Ulusal Pediatrik Kanser Kayıtlarında 2002-2006 yllı verilerine göre \%7,73 oranında olup dördüncü sıradadır (2). Yenidoğan döneminden itibaren sık görülen NBL, erken evrelerde ve bir yaşından küçüklerde iyi seyirli iken büyük çocuklarda ve metastatik evrede mortalite nedenidir. Sık görülen ve farklı klinik yüzler sergileyen nöroblastik tümörlerin epidemiyolojik ve klinik özelliklerinin iyi tanınması önemlidir.

$\mathrm{Bu}$ çalışmanın amacı, merkezimizde NBL tanısı alan hastaların yaşlarına ve primer tümör yerleşimine göre semptomlarını, yakınma sürelerini ve tanısal klinik ipuçlarını belirlemektir. 


\section{Gereç ve Yöntem}

Bu çalışmada Uludağ Üniversitesi Tıp Fakültesi Pediatrik Onkoloji Bilim Dalı'nda 1.1.1996-31.12.2012 tarihleri arasında NBL tanımlanan hastaların kayıtları retrospektif olarak değerlendirildi. Yaş, cinsiyet, başvuru yakınması, primer tümör ve metastazlara ait yakınma ve bulgular, semptomların süresi ve tümör yerleșimi saptandı. Tanı alma şekli, tam kan sayımı, laktik dehidrogenaz düzeyi, idrarda vanilmandelik asit (VMA), kemik iliği bulguları değerlendirildi. Uluslararası nöroblastom evreleme sistemine ("International Neuroblastoma Staging System"=INSS) göre hastalık evreleri belirlendi $(1,3)$. Hasta yaşı, yakınma süresi gibi parametrik veriler ortalama ve standart sapmaları ile verildi. Tümör yerleşimi, tanımlanan yakınma ve bulgular, tutulum görülen bölgeler ve evrelere dağlım yüzde ile ifade edildi. İstatistiksel değerlendirmeler için SPSS istatistik programı (versiyon 16.0) kullanıldı. Ortalamalar, iki ortalama arasındaki farkın önemlilik t-testi ile; yakınmaların yaş gruplarına, yerleșime ve diğer alt gruplara göre dağılımları ise Ki-kare testi ile karşıllaştırıldı.

\section{Bulgular}

NBL ve ganglionöroblastom tanıSı alan hastalar NBL tümör grubu olarak belirlendi. Araştırılan 16 yıllık dönemde NBL tanımlanan 115 çocuk hastanın verileri değerlendirildi. NBL'lu hastaların ortalama tanı yașı $2,57 \pm 2,49$ yaş, ortanca değer 21 ay olup en küçük hasta yenidoğan bebek, en büyük hasta 11,8 yaşında idi (Tablo 1). Neonatal dönemde tanı alan hastaların oranı \%6,9 bulundu. Hastaların \%32'si bir yașından, \%43'ü iki yașından, \%89'u beș yașından küçüktü (Şekil 1). NBL'lu hastaların \%53'ü kı, \%47'si erkekti. Erkek/kız oranı 0,9 bulundu.

Hastaların \%74.8'inde $(n=86)$ karında kitle saptandı. Bu olguların \%66'sı sürrenal, \%8,8'i sürrenal dışı abdominal

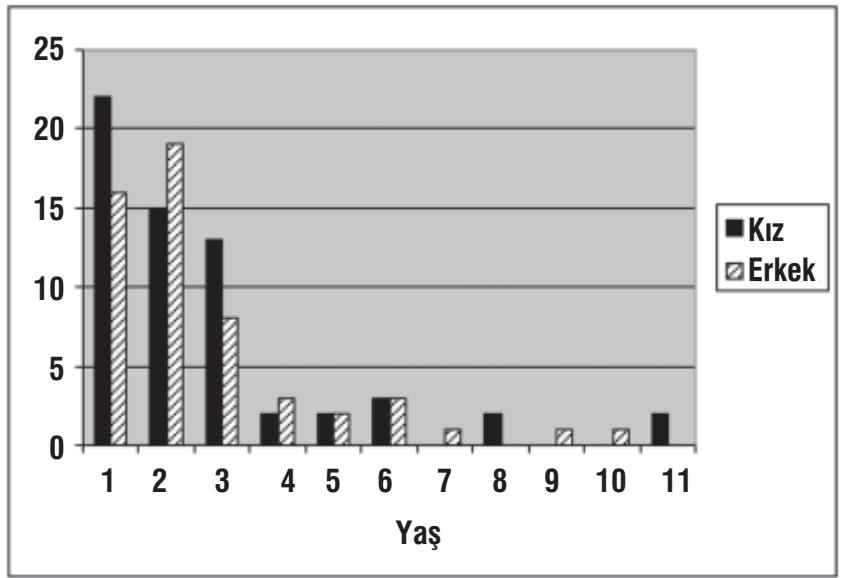

Şekil 1. Yaş ve cinsiyet dağılımı tümörlerdi. Olguların \%12'sinde $(n=14)$ paraspinal kitle saptandı. Kitle yerleşimi \%43'ünde $(n=6)$ torakal, $\% 14$ 'ünde $(n=2)$ torakolumbal, \%36'sında $(n=5)$ lumbal ve $\% 7$ 'sinde $(n=1)$ lumbosakral paraspinal ganglionlar düzeyinde idi. Arka mediastende kitle hastaların \%7'sinde $(n=8)$ gözlendi. Pelvik kitle $\% 3,5$ 'inde $(n=4)$, servikal kitle \%1,7'sinde $(n=2)$ saptandı. Seride tek hastada başka primer bölge olmadan intrakraniyal yerleşimde NBL tanımlandı (Tablo 1).

Tümör evresi olguların \%30,4'ünde evre 1 ve 2, $\% 13$ 'ünde evre 3, \%46,2'sinde evre 4 ve $\% 10,4$ 'ünde evre 4S olarak belirlendi. Metastatik hastalık saptanan NBL olgularında en sık gözlenen yayılım alanları uzak

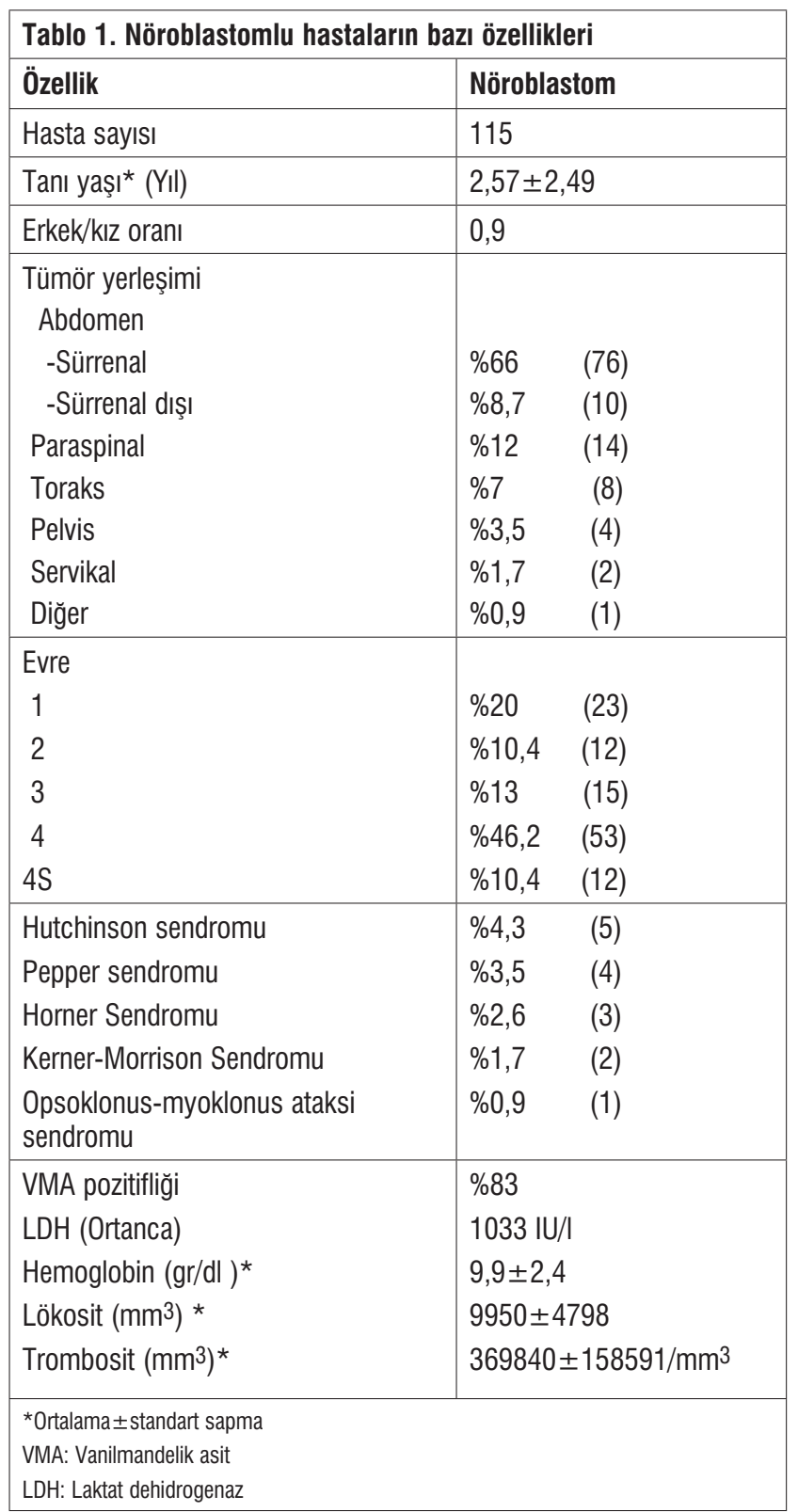


lenf düğümleri (\%51), kemik iliği (\%29), kemik (\%24) ve karaciğer (\%24) olarak belirlendi. Yaygın hastalık durumunda akciğer tutulumu hastaların \%8'inde tanımlandı. Primer santral sinir sistemi yerleşimli tek olgu dışında tanıda beyin metastazı yoktu (Şekil 2). Hastaların tanıdaki yaşları ve evrelere dağılımı Şekil 3'te verildi. Evre 4 hastalık tanımlanan çocukların yaş ortalaması 3,26 $\pm 2,52$ yaş olup grup ortalamasından yüksekti $(p=0,3)$.

Olguların \%11'i ( $n=13)$ klinik bulgular, sitoloji ve VMA değerleri ile tanı aldı. Serideki hastaların \%89'unda $(n=102)$ doku örneklerinden histopatolojik tanı konuldu. İdrarda kantitatif VMA yüksekliği cerrahi girişim öncesinde bakılan olguların \%83'ünde saptandı.

Hasta grubunda NBL tanısına ulaştıran yakınma süreleri iki gün ile bir yıl arasında değişmekteydi. Ortanca yakınma

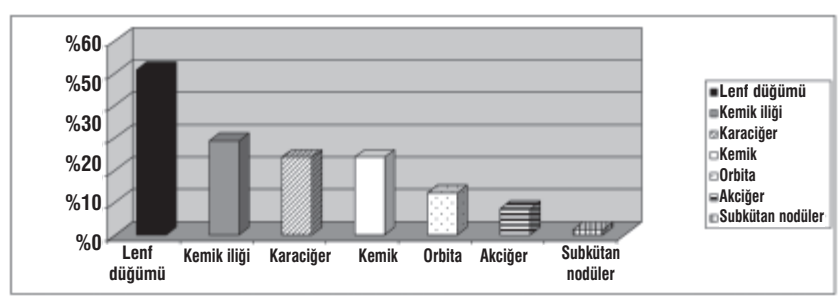

Şekil 2. Nöroblastomda metastaz bölgeleri

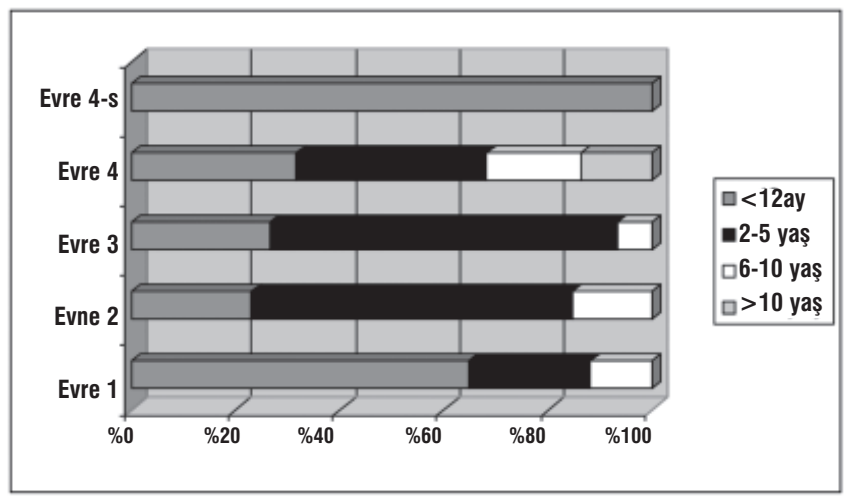

Şekil 3. Nöroblastomlu hastalarda yaş ve evre dağııımı

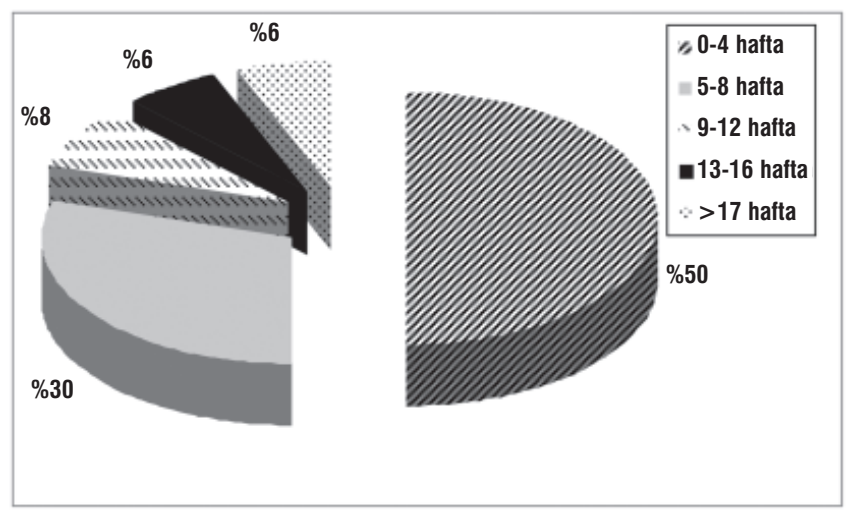

Şekil 4. Nöroblastomlu hastalarda yakınma süreleri süresi 6,5 hafta olarak tanımlandı. Olguların \%50'sinde dört haftadan kısa, \%80'inde ise iki aydan kısa yakınma süresi saptandı (Şekil 4).

Hastaların hekime başvuru yakınmaları Tablo 2'de özetlendi. Hastaların \%8,7'sinde $(n=10) \quad N B L$ tanısı rastlantısal olarak konuldu. Bu çocukların çoğunluğunda rutin gebelik izlemi için veya postnatal kontrol amacıyla yapılan abdominal ultrasonografide kitle görüldü. Başka nedenle çekilen akciğer radyografisinde kitle görülen iki olgu ve ekokardiyografi sırasında sürrenal lojda kitle tanımlanan bir olgu mevcuttu.

Bu seride en sık başvuru yakınmaları solukluk, halsizlik, karın şişliği ve karın ağrısı olarak belirlendi. Kemik ağrısı, topallama ve yürüyememe yakınmaları olguların \%21'inde başvuru nedeni olarak saptandı. Dirençli veya nedeni bulunamayan ateş \%19 oranında tanımlandı. Solunum güçlüğü ve solunum sayısında artış hastaların \%10'unda ana yakınma olarak saptandı. Solunum sıkıntısı ve hııltı, torakal kitleli hastaların yarısında gözlendi $(n=4)$. Dispne

Tablo 2. Nöroblastomlu hastalarda başvuru yakınmaları

\begin{tabular}{|l|c|}
\hline Yakınma & Görülme yüzdesi * \\
\hline Solukluk, halsizlik & 46 \\
Karın şişliği & 43 \\
Karın ağrısı & 40 \\
Anoreksi & 24 \\
Kemik ağrısı & 21 \\
Ateş & 19 \\
Huzursuzluk & 17 \\
Kusma & 17 \\
Kilo kaybı & 13 \\
Solunum sıkıntısı & 10 \\
Ekzoftalmus & 9 \\
Kuvvet kaybı & 7 \\
Ishal & 5 \\
Sııt ağrıSı & 3,5 \\
Boyunda şişlik & 2,6 \\
Idrar yapamama & 2,6 \\
Idrar ve gaita inkontinansı & 2,6 \\
Terleme & 2,6 \\
Subkütan nodüller & 1,8 \\
Sarılık & 0,9 \\
Ataksi & 0,9 \\
Görme kaybı & 0,9 \\
Hırıtı & 0,9 \\
Nöbet geçirme & 0,9 \\
Yakınması yok (Rastlantısal) & 8,7 \\
\hline *Aynı hastada birden fazla yakınma görülmüștür \\
\hline
\end{tabular}


gözlenen diğer hastalar abdominal hastalıkla başvurdu. Göz çevresinde morarma olarak ifade edilen periorbital ekimoz tek olarak veya ekzoftalmusla beraber $\% 9$ oranında gözlendi. Olguların \%7'sinde daha önce normal olan bir çocukta ani gelişen ve artış gösteren kuvvet kaybı tanımlandı. Bu olguların yarısında kuvvet azlığı çıkmadan önce gelişen radiküler ağrı tanımlanıyordu. Kord basısı tanımlanan sekiz çocuktan ikisinde idrar ve gaita kontrolünde kayıp mevcuttu. Tek yakınması ishal veya kusma olan hasta sayısı sınırlı idi. Hastaların \%24'ünde diğer yakınmalara eşlik eden anoreksi, \%17'sinde ise kilo kaybı olduğu belirlendi. NBL tanısı alan hasta grubunda nadir görülen yakınma ve bulgular arasında idrar yapamama, sarılık, ani ve aşırı terleme mevcuttu. Birer olgu görme kaybı, ataksi ve ateşsiz dönemde nöbet yakınması ile başvurdu. Yakınma ve bulguların tümör yerleșimi ile ilișkisi incelendi. Kord basısı bulguları paraspinal tümörlere özgü olmakla birlikte diğer yakınmaların tümör yerleşimi ile ilişkili olmadığı belirlendi ( $p>0,05)$. Başvuru yakınmalarının hastalığın evresine göre dağılımı Şekil 5'te verildi. Hastaların \%42,6'sında bir veya iki başvuru yakınması olduğu belirlendi. Serideki olguların \%48,7'sinde öyküde en az üç ana yakınma tanımlandı.

Kan sayımı ve tümör belirteçlerinin dağılımı değerlendirildi. Tanı sırasında hemoglobin $(\mathrm{Hb})$ düzeyleri 4,39-17 gr/dl sınırları arasında değişmekteydi. Ortalama $\mathrm{Hb}$ düzeyi $9,9 \pm 2,4 \mathrm{gr} / \mathrm{dl}$ olarak belirlendi. $\mathrm{Hb}$ değeri olguların \%25'inde $8 \mathrm{gr} / \mathrm{dl}$ 'den, \%56'sında $11 \mathrm{gr} / \mathrm{dl}$ 'den düşüktü. Lökosit sayımları ortalama $9950 \pm 4798 / \mathrm{mm}^{3}$ (sınırlar: 1800-15900/mm3) bulundu. Lökopenik olan tek hasta $(\% 0,9)$ mevcuttu. Ortalama trombosit sayımı $369,000 \pm 158,591 / \mathrm{mm}^{3}$ (sınıllar: 61,000-793,000/mm3) olarak saptandı. Trombosit sayımı 100,000/ mm3 sınırından düşük olan hasta oranı \%4 bulundu.

LDH düzeyleri 195-8250 IU/I sınırları arasında değişmiş olup ortanca değer 1033 bulundu. Olguların \%20'sinde LDH yaşa göre normal sınırlarda idi. Hastaların \%16'sında 1000 IU/L'den, \%15'inde 2000 IU/L'den yüksek LDH

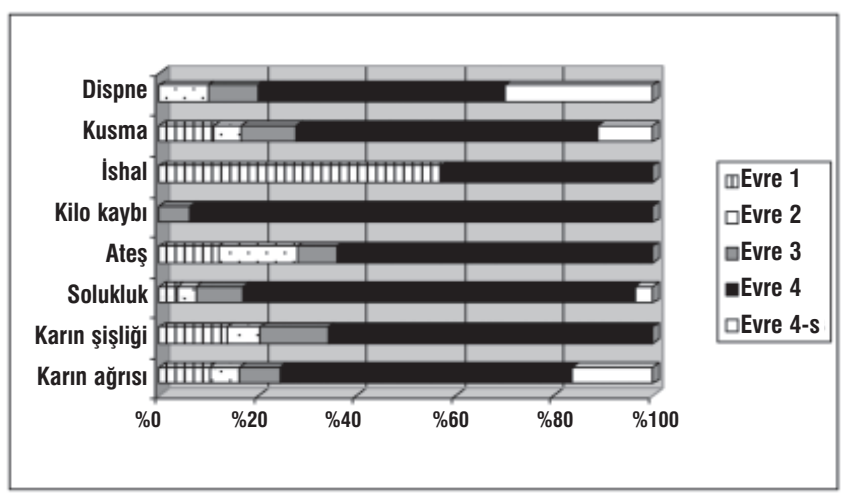

Şekil 5. Nöroblastomda başvuru yakınmalarının evrelere göre dağılımı düzeyi olduğu saptandı. Idrarda katekolamin metabolitleri incelendi. VMA kantitatif ölçümü sonuçları değerlendirildi. Başka ön tanılarla opere olup VMA istenmeyen ve postoperatif dönemde geldiğinde ölçüm normal bulunan olgular grubun \%17'sini $(n=20)$ oluşturdu. Cerrahi öncesinde ölçüm yapılarak VMA/kreatinin değerinde artma saptanan hasta oranı \%83 $(n=79)$ bulundu.

\section{Tartışma}

NBL çocukluk çağı kanserlerinin \%7'sini oluşturduğu halde çocukta kanser ölümlerinin \%15'inden sorumludur (1). Türk Pediatrik Onkoloji Grubu (TPOG) ve Türk Pediatrik Hematoloji Derneği (TPHD) pediatrik tümör kayıtları çalışmasının ön verileri sempatik sinir sistemi tümörlerinin 0-18 yaş grubu kanserlerinin \%7,7'sini oluşturduğunu, 0-4 yaş arasında ise bu oranın \%14,3 olduğunu göstermektedir (2). Bu dağılım ile NBL dördüncü en sık çocuk kanseridir. NBL çocukluk çağının tümör dışı hastalıklarını ve çeşitli kanserlerin bulgularını taklit eder. Bu nedenle, tüm hekimlerin NBL'lu çocuklarla karşıllaşması mümkündür. Serimiz NBL'un lokal ve yaygın hastalık bulgularını yansıtmaktadır.

Bu seride NBL'un ortalama tanı yaşı 2,57 $\pm 2,49$ yaş, ortanca tanı yaşı 21 aydır. Hastaların \%6,9'u yenidoğan döneminde, \%32'si bir yaşından önce tanı almıştır. En büyük hasta 12 yaşındadır. Veriler NBL'un küçük çocukların tümörü olduğunu ortaya koymaktadır. Gözlenen yaş dağıımı tipiktir. Geniş serilerde ortanca tanı yaşı 19 ay olarak tanımlanmaktadır. NBL yenidoğanlarda en sık görülen kanserdir (4). Kız ve erkek çocuklarda benzer oranda görülmektedir. Lenfoma ve lösemide gözlenen erkek çocuklardaki insidans fazlalığı NBL'da yoktur.

NBL'un klinik tablosu primer tümörün bölgesine göre değişir. Tümör sempatik sinir sistemi dokusunun normal olarak bulunduğu adrenal medulla, sempatik yan zincir veya viseral ganglionlardan başlayabilir. Sunulan seride 115 hastanın dörtte üçünde karında kitle saptanmıştır. Bu kitlelerin \%66'sı sürrenal yerleşimli, \%8,7'si ise sürrenal dışı abdominal kitlelerdir. Toraksta kitle \%14 oranında gözlendi. Bunların yarısında paraspinal yerleşim tanımlandı. Torakoabdominal paraspinal kitlelerin toplam oranı \%12 bulundu. Pelvik ve servikal yerleşimde kitle serinin \%5 kadarında gözlendi.

NBL tanısı alan çocuklarda önceden bilinen sistemik hastalık yoktu. Ortanca yakınma süresi 6,5 hafta olarak tanımlandı. Hastaların \%50'sinde dört haftadan kısa, \%80'inde sekiz haftadan kısa yakınma süresi gözlendi. Bu veriler tümörün hızı ilerlediğini düșündürür.

Sunulan serideki hastaların \%60'a yakını evre 3 ve evre 4 olarak tanımlanmıştır. Olguların \%46'sında yaygın uzak 
metastazlar saptanmıştır. Bir yaşından küçük hastalara özgü olan evre 4 S hastalık \%10,4 oranındadır. Sonuç olarak hastaların \%70'inde lenf düğümü, kemik iliği, karaciğer, kemik, periorbital bölge, akciğer ve subkütan yerleşimde tutulum bulguları tanımlanmıştır.

Geliş yakınma ve bulguları primer tümör yerleşiminden daha fazla hastalığın yaygınlığına göre değişmektedir. Lokal hastalık hiç semptom vermeden rastlantısal olarak tanımlanabilir. Sunulan gruptaki hastaların \%8,7'sinde tümöre ait yakınma olmadan tanı konmuştur. Bu hastaların tümü erken evrede tanı almıştır. Hastaların küçük süt çocukları olması dikkat çekicidir. Ultrasonografinin kolay ve rutin uygulanması nedeniyle prenatal dönemden itibaren saptanan kitlelerin sayısı artmaktadır. Kardiyak eko yapılırken karında kitle saptanan hastamız vardır.

NBL tanısı alan olguların \%42'sinde bir veya iki ana yakınma tanımlanmıştır. Hastaların \%48,7'sinde ise üçten fazla majör yakınma söz konusudur. Primer tümör yerleșimi ve tümör yayılımının ortak sonucu olarak NBL'da çok çeșitli yakınmalar ve bulgular söz konusudur. Hastaların \%43'ünde karın șișliği, \%40'ında ise karın ağrısı tanımlanması çoğunluğu abdominal retroperitoneal kitle ile gelen bu hasta grubu için beklenen bulgudur $(5,6)$. Abdomende sert, ağrısız kitle çoğu hastada palpe edilmiştir. Kitlenin orta hattı geçerek karşıya yayılması renal kitleden NBL'a yaklaştıran bir tanısal bulgudur. Karın ağrısı ve/veya karın şişliği gözlenen hastaların üçte ikisinde ek olarak kusma, solukluk, halsizlik, ateş yükselmesi, kilo kaybı ve devam eden anoreksi tanımlanmıştır. Anemiye bağlı semptomlar ilk geliş yakınmaları olabilir. Tümöral tutulum sonucunda gelişen kemik iliği yetmezliği veya tümör içine kanama anemiye neden olur. Kilo kaybı, huzursuzluk, ateş yaygın hastalığın bulgularıdır $(1,6)$. Daha fazla yakınmanın eklenmesi tümörün sistemik etkilerini ve metastatik hastalığı destekleyen bulgulardır. Serimizde en fazla tanımlanan yakınmanın solukluk ve yorulma olması da yarısına yakını evre 4 olarak tanımlanan hastaların durumu ile uyușmaktadır.

Sadece ishal serimizde \%5 oranında gözlenmiştir. Vazoaktif intestinal polipeptid salınımına bağlı diyare nöral krest tümörlerinin \%7-9'unda bildirilmiştir $(6,7)$. Daha çok ganglionörom veya ganglionöroblastoma eşlik eder. NBL'da görülen hipokalemi ile seyreden dirençli, sulu diyare bir paraneoplastik sendromdur (Kerner-Morrison Sendromu). Tümör çıkarıldığında diyare düzelmektedir.

Idrar yapamama yakınması ile gelen hastaların hepsinde pelvik retrovezikal kitle görülmüştür. Bu kitlelerin aort bifurkasyonuna yakın paraganglion olan Zuckerkandl organından veya retroperitoneal sempatik zincirden geliştiği kabul edilmektedir (8). Akut idrar retansiyonu olan çocuklarda üriner enfeksiyon, alt üriner sistemde taş, travma, konstipasyon gibi daha sık akla gelen nedenlerle birlikte pelvik NBL ayırıcı tanıda yer alır (9). Presakral kitlelerden başka üretere bası yapan abdominal kitleler de aynı yakınmaya yol açabilir. Bu olgularda hidronefroz görülmesi uyarıcı bir bulgu olmalıdır. Intraabdominal bası sonucunda gözlenen başka bir yakınma sarılıktır (1). Çocukluk çağında tümörlere bağı tıkanma sarılığı yetişkine göre nadirdir. Bu seride iki hastada karın şişliğine ek olarak ikter tanımlanmıștır.

NBL'lu çocuklarda karın şişliğinin başka bir nedeni hepatomegalidir. Hızı ıüyüyen karaciğer küçük bebeklerde NBL'u düşündürmelidir. Çünkü hepatoblastoma göre NBL daha sık gözlenir. Adrenal NBL ve metastaza bağlı masif hepatomegali durumu Pepper sendromu olarak bilinir $(1,6)$. Merkezimizde bu tablo tüm grupta $\% 3,5$, evre 4 S olgular dikkate alındığında \%25 oranında görülmüştür. Hastalarda diyafragmanın yukarı itilmesi ve aşırı abdominal gerginlik solunum sıkıntısına yol açar ve hatta mortalite nedeni olabilir.

Serimizdeki evre 4 ve $4 S$ abdominal tümörlerde gözlenen takipne ve dispne, arka mediasten kitlelerinde belirgin değildir. Hırıltı, öksürük ve tekrarlayan solunum yolu yakınmaları mediastinal NBL olgularının \%50'sinde görülmüştür. Göğüs ağrısı ve dispne saptanmamıştır. Torakal NBL'lu olguların yarısı paraspinal yerleşimde kitle ile gelmiş olup bu hastalarda nörolojik bulgular saptanmıştır. Literatürdeki veriler deneyimimizi desteklemektedir $(1,6)$. Arka mediastendeki küçük kitleler asemptomatik olabilir. Torakal NBL olgularının sunulduğu bir araștırmada 87 hastadan 20'sinde hiçbiryakınma olmadığı bildirilmiştir. Buna karşılık aynı yayında semptomatik kord basısı \%25,3'ünde bildirilmiştir (10). Servikal sempatik ganglionlardan köken alan NBL Horner sendromuna neden olur. Servikal yerleşimli NBL'da tanımlanan Horner Sendromu üst mediasten kitlelerinde de görülür. Sunduğumuz grupta postoperatif dönemde olguları \%2,6'sında görülmekle birlikte, bașvuruda Horner sendromu olan hasta yoktur. Nadiren NBL süperior vena kava sendromuna neden olur.

Paravertebral kitleler intervertebral foramene doğru büyüme eğilimindedir. Halter veya kum saati görünümündeki bu kitlelerin intraspinal uzanımları spinal kord basısı sonucunda ekstremitede güçsüzlük, paralizi, ve inkontinans gibi nörolojik semptomlara yol açar (6). Paraspinal tümörler serimizdeki olguların \%12'sini $(n=14)$ oluşturmaktadır. Bu hastaların sekizinde (\%57) medulla spinalis basısı görülmüştür. Kuvvet azlığına ek olarak idrar ve gaita inkontinansı 2 olguda mevcuttur. Nörolojik kayıplar gelişmeden önce bu hastaların yarısında sırt ve bele yayılan radiküler ağı tanımlanmaktadır. Medulla spinalis basısı bir onkolojik acil durumdur. Dinlenmekle geçmeyen, radiküler ağrılar son derece önemli ve uyarıcı bulgulardır. 
Bu çocuklarda mutlaka nörolojik muayene yapılmalı ve manyetik rezonans görüntüleme ile kitle ve vertebrada çökme araştııımalıdır. Tanı gecikirse kuvvet kaybı kalıcı olacaktır. Merkezimizdeki paraspinal NBL olgularının \%43'ü nörolojik kayıp gelişmeden tanı almıştır. Paraspinal tümörlerden intraspinal alana uzanım literatürde \%15-40 oranında bildirilmiştir $(1,6,11)$.

Hastalarımızda medulla spinalis basısına ek olarak ataksi ve opsoklonus, ani görme kaybı ve nöbet geçirme yakınmaları birer hastada başvuru sebebi olmuştur. Opsoklonus, miyoklonus ve ataksi NBL'da tanımlanan paraneoplastik sendromlardan biridir (12). Bu çocuklarda ani spontan, konjuge göz hareketleri, ekstremite ve gövde kaslarında düzensiz kasılmalar gözlenir. Serimizde $\% 0,9$ oranında saptanan bu bulgu bazı yayınlarda \%5-9 oranında bildirilmektedir $(1,12)$. Optik sinirlere bası, evre 4 NBL'lu olgumuzda körlüğe neden olmuștur. Primer serebral NBL tanımlanan hastanın geliş yakınması nöbet geçirmedir. Deneyimlerimize göre olguların \%9'unda $(n=11)$ nörolojik bulgular ön plandadır. Intrakraniyal kitle ayırıcı tanısında NBL yer almalıdır. Kitlenin hemorajik ve kalsifik olması NBL'u destekler. NBL primer nörolojik hastalıkları ile karışabilir. Açıklanamayan nörolojik bulgusu olan çocuklarda NBL araştııımalıdır.

NBL'da ekstra abdominal bulgular daha karmașıktır. Illk kitle karında olduğu halde hastalar farklı bulgularla gelebilirler. NBL kemik iliğine, uzun kemiklerin korteksine, yassı kemiklere, bölgesel lenf düğümlerine, karaciğere ve subkütan dokulara metastaz yapar. Sunulan 115 hastanın \%21'inde şiddetli bacak ağrısı, basamama, topallama, dokunulunca ağlama gibi yakınmalar tümörün kemik metastazlarına ait belirtilerdir. Bu hasta grubunda olguların \%9'unda rakun gözü olarak bilinen orbita tutulumuna bağlı periorbital ekimoz ve ekzoftalmus saptanmıştır. Orbita NBL'un tipik metastaz yeridir, orbita kemiklerine yayılım konusunda açıklanamayan bir eğilim gözlenir $(1,6,11)$. Kemik ve orbita tutulumu olan hastaların \%30'unda ayrıca saçlı deride ve kalvarium kemiklerinde ağrılı kitleler görülmüştür. Kemik metastazı olan her hastada palpe edilen kemik şişliği yoktur. İskelet sistemine metastaz çok şiddetli ağrılara neden olur. Bu hastaların bazıları ağrı nedeniyle incelenirken abdominal kitle tanımlanmıştır. Primer adrenal nöroblastomu ile birlikte yaygın iskelet metastazları, proptozis ve ağrının birlikte olması Hutchinson sendromu olarak bilinir. Hastalarımızın \%4,3'ü bu klinikle başvurmuştur. Fizik incelemede kolay tanınan bu aşamadaki hastalarda prognoz kötüdür. NBL'lu çocuklarda periost reaksiyonundan patolojik kırıklara kadar değișen radyolojik bulgular görülür. Metastatik kemik lezyonları Ewing sarkoma, rabdomiyosarkom, lösemi ve lenfoma tanılı hastalarda da olur ve ayırıcı tanı gerektirir.
Bu seride hastaların \%29'unda saptanmış olan kemik iliği tutulumu da ağrıya katkıda bulunmuştur. Kemik iliği invazyonu ve kemik yıkımına ek olarak kalvarium kemiklerinde tutulum sonucunda gelișen epidural kitleler ve kafa içi basınç artışı şiddetli ağrılarına neden olur. Olguların üçte ikisi ciddi ağrı yakınması ile hekime gelmiştir. Metastatik NBL'lu çocuklarda diğer abdominal kitleli hastalara kıyasla ağı şiddeti çok daha fazladır. Narkotik analjeziklere gerek duyulur.

Aşırı katekolamin yapımına bağı olduğu yorumlanan ani ve fazla terleme olguların \%1'inde ilk başvuru nedeni olmuştur. Kitlenin renal vasküler yapılara basısı ve katekolamin yüksekliğine bağlı olarak NBL'lu çocukların \%30 kadarında hipertansiyon gözlenebilir. Nadir bulgular arasında subkütan nodüller hatıllanmalıdır $(1,13)$. Vasküler lezyonlardan ayırt edilmesi önemlidir.

NBL'da ilk geliş yakınmaları son derece değişkendir. Ayrıntılı öykü ve tam fizik incelemeye ek olarak laboratuar verileri de NBL için destekleyicidir. Tam kan sayımı bulguları kemik iliği tutulumunun \%29 olduğu bu hasta grubunda, aneminin önemli bir bulgu olduğunu ortaya koymaktadır. Hastalarımızın \%56'sında Hb değeri $11 \mathrm{gr} / d l$ 'den düşüktür ve NBL tanısı alan her dört çocuktan birinde $8 \mathrm{gr} / \mathrm{dl}$ 'nin altındadır. Buna karşılık pansitopeni gözlenen hasta yoktur. Derin anemisi olan beş yaşından küçük çocuklarda NBL ayırıcı tanıda yer almalıdır.

NBL'lu çocukların \%90'dan fazlasında katekolaminler ve yan ürünlerinin düzeyi artmıştır $(1,6,14)$. Merkezimizde tanı alan hastalarda idrarda VMA yüksekliği \%83 oranında saptanmıştır. Vanilyası diyet koșulları sağlanarak 24 saatlik idrarda kantitatif analiz yapılabildiği gibi spot idrar örneğinden inceleme de mümkündür. NBL ön tanısı olan bütün hastalarda cerrahi girişimden önce katekolamin metabolitleri bakılmalıdır. Hastanın tanısı kadar izleminde de bu veri çok kıymetlidir.

Bulgularımız serum LDH düzeyinin NBL tanımlanan çocukların \%80'inde yüksek olduğunu ortaya koymaktadır. LDH artıșı tümör yükü ve ileri evre ile korelâsyon göstermektedir.

Klinik davranıșı değișken bir tümör olan NBL aile hekimlerinden cerrahi branşlara kadar her hekime başvuru nedeni olmaktadır. Serimizdeki çocukların \%80'inde yakınmalar son 8 haftada tanımlanmıştır. NBL'da tümörün anatomik yerleşimi farklı olduğu gibi, yaygın hastalık bulguları da her sistemle ilgilidir. Bu durum tanı alma süresini uzatabilir. Verilerimiz NBL'lu çocuklarda karın ağrısı ve karın şişliği ile derin aneminin birlikte olduğunu göstermektedir. Metastatik orbita ve iskelet bulguları olduğunda klinik tanı daha çabuk konmaktadır. Illk iki yaştaki ağılı ve ıstıraplı çocuklar NBL açısından dikkatle değerlendirilmelidir. Özellikle beş yaşından küçük çocuklarda açıklanamayan her yakınmada NBL ayırıcı tanıda yer almalıdır. 


\section{Kaynaklar}

1. Brodeur GM, Hogarty MD, Mosse YP. Neuroblastoma. In:Pizzo PA, Poplack DG (eds). Principles and Practice of Pediatric Oncology. 6th edition. Philadelphia: Lippincott Williams\&Wilkins; 2011. p.886-922.

2. Kutluk T. Çocukluk çağı kanserlerinin epidemiyolojisi. In: Özkan A (ed):Pediatrik Onkoloji. Birinci baskı. Istanbul: Nobel Tip Kitabevleri; 2009. s.3-13.

3. Brisse HJ, McCarville MB, Granata C, Krug KB, WoottonGorges SL, Kanegawa $\mathrm{K}$ et al. Guidelines for imaging and staging of neuroblastic tumors: Consensus report from the International Neuroblastoma Risk Group Project. Radiology 2011;261:243-57.

4. Fisher JP, Tweddle DA. Neonatal neuroblastoma. Semin Fetal Neonatal Med 2012;17:207-15.

5. Chu CM, Rasalkar DD, Hu YJ, Cheng FWT, Chu WCW. Clinical presentations and imaging findings of neuroblastoma beyond abdominal mass and a review of imaging algorithm. $\mathrm{Br} \mathrm{J}$ Radiol 2011;84:81-91.

6. Olgun N, Aksoylar S.Nöroblastom.In: Özkan A (ed):Pediatrik Onkoloji. Birinci baskı. Istanbul: Nobel Tıp Kitabevleri; 2009.s.763-86.
7. David R, Lamki N, Fan S, Singleton EB, Eftekhari F, Shirkhoda $A$ et al. The many faces of neuroblastoma. Radiographics 1989;9:859-82.

8. Rasmussen A, Muniz AE, King B. Neuroblastoma causing acute urinary retention: a rare presentation. J Emerg Med 2010;39:602-6.

9. McHugh K. Renal and adrenal tumours in children. Cancer Imaging 2007;7:41-51.

10. Demir HA, Yalçin B, Büyükpamukçu N, Kale G, Varan A, Akyüz $C$ et al. Thoracic neuroblastic tumors in childhood. Pediatr Blood Cancer 2010;54:885-9.

11. D’Ambrosio N, Lyo JK, Young RJ,Haque SS, Karimi S. Imaging of metastatic CNS neuroblastoma. AJR Am J Roentgenol 2010;194:1223-9.

12. Brunklaus A, Pohl K, Zuberi SM, de Sousa C. Outcome and prognostic features in opsoclonus-myoclonus syndrome from infancy to adult life. Pediatrics 2011;128:e388-94.

13. Demirkaya $M$, Sevinir $B$, Yalçınkaya U. Congenital neuroblastoma presenting with subcutaneous nodules. Turkiye Klinikleri J Med Sci 2008;28:995-8.

14. Sandoval JA, Malkas LH, Hickey RJ. Clinical significance of serum biomarkers in pediatric mediastinal and abdominal tumors. Int J Mol Sci 2012;13:1126-53. 